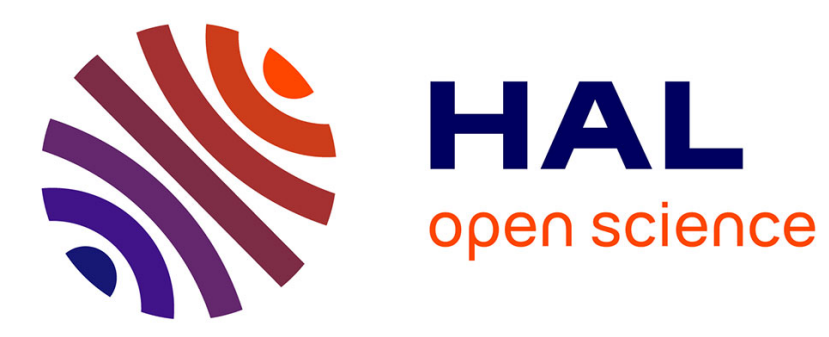

\title{
Critical angles in DC magnetron glad thin films
}

Ahcene Siad, Aurélien Besnard, Corinne Nouveau, Philippe Jacquet

\section{To cite this version:}

Ahcene Siad, Aurélien Besnard, Corinne Nouveau, Philippe Jacquet. Critical angles in DC magnetron glad thin films. Vacuum, 2016, 131, pp.305-311. 10.1016/j.vacuum.2016.07.012 . hal-01365494

\section{HAL Id: hal-01365494 \\ https://hal.science/hal-01365494}

Submitted on 22 Nov 2017

HAL is a multi-disciplinary open access archive for the deposit and dissemination of scientific research documents, whether they are published or not. The documents may come from teaching and research institutions in France or abroad, or from public or private research centers.
L'archive ouverte pluridisciplinaire HAL, est destinée au dépôt et à la diffusion de documents scientifiques de niveau recherche, publiés ou non, émanant des établissements d'enseignement et de recherche français ou étrangers, des laboratoires publics ou privés. 


\title{
Critical angles in DC magnetron glad thin films
}

\author{
Ahcene Siad ${ }^{\mathrm{a}}$, Aurélien Besnard ${ }^{\mathrm{a}}{ }^{*}$, Corinne Nouveau ${ }^{\mathrm{a}}$, Philippe Jacquet ${ }^{\mathrm{a}, \mathrm{b}}$ \\ a Arts et Metiers ParisTech, LaBoMaP, Rue Porte de Paris, F-71250, Cluny, France \\ ${ }^{\mathrm{b}}$ Pôle Matériaux et structures, ECAM Lyon, 40 Montée Saint Barthélemy, Université de Lyon, F-69321, Lyon Cedex, France
}

\section{A R T I C L E I N F O}

\section{Article history:}

Received 28 January 2016

Received in revised form

7 July 2016

Accepted 8 July 2016

Available online 12 July 2016

\section{Keywords:}

DC magnetron sputtering

GLAD

$\mathrm{Al}$

Ti

Simulation

\begin{abstract}
A B S T R A C T
The objective of this study is to examine the sudden drop in properties of aluminum, titanium and chromium thin films prepared by the glancing angle deposition method. The thin films were deposited by DC magnetron sputtering under identical deposition conditions. A substrate-holder with seven different orientations with respect to the target normal was used. The thickness and the column tilt angles $(\beta)$ of the thin films were determined by scanning electron microscopy. The residual stress of the thin films was evaluated using the wafer curvature technique and calculated by the Stoney's formula. The thickness variation and column tilt angle versus the orientation of the substrate indicated that the critical point is around $60^{\circ}$ for all metallic materials and a critical angle of $60^{\circ}$ is also found for the residual stress. Simulations of the particles transport are compared to the experimental data and moderate the critical angles analyses.
\end{abstract}

\section{Introduction}

In the recent years, glancing angle deposition (GLAD) technique was employed to control the structure of thin films. By definition, GLAD [1,2] is a physical vapor deposition technique in which the substrate is oriented with respect to the target normal at an angle $(\alpha)$. Also, it undergoes a movement of rotation on itself at an angle $\varphi$. According to the variation of these parameters $(\alpha, \varphi)$, many coatings grow in the form of inclined columns [3,4], zigzag columns $[5,6]$, nano-spirals $[7,8]$, slanted posts [9], nanotubes [10] and branched nano columns [11]. Among the applications of architected films, one can cite optical sensors [12], nano mechanical [13], pressure sensors [14], and field emitters [15]. Most of the researches concerning GLAD layers were applied to pure material such as Si [7], Cr [4,16], Pt [17], Ta [11,18], W [7], Ti [19] and Co [7]. Others preferred to work on oxides such as $\mathrm{TiO}_{2}[20,21], \mathrm{SiO}_{2}[21]$, $\mathrm{ZrO}_{2}$ [22], or sulfides such as $\mathrm{ZnS}$ [23] and $\mathrm{Sb}_{2} \mathrm{~S}_{3}$ [24].

Most of the properties present a critical point (or zone) around $50^{\circ}$ where a change is observed [25-27]. In these papers, the results are often compared to the atom incidence angle, which is assumed to be equal to the substrate orientation angle and the critical zone is only noticed as a particular characteristic. Due to the

\footnotetext{
* Corresponding author.

E-mail address: aurelien.besnard@ensam.eu (A. Besnard).
}

numerous deposition conditions, chamber and target geometry, material deposited, etc., a global understanding of the mechanisms ruling the critical zone is limited.

The aim of this paper is to highlight the presence of critical zones in some properties of inclined columnar coatings. To reduce the number of variables in the system, different substrate inclinations are used during one deposition under constant conditions (temperature, pressure, discharge power, etc.) for three pure metallic coatings. For each property the critical angle is discussed. Simulations are computed and give the number of particles detected for each angle, the angle of incidence and the energy of the impinging particles.

\section{Experimental}

Aluminum, chromium and titanium thin films were deposited on (100) Si substrates $(20 \mathrm{~mm} \times 10 \mathrm{~mm} \times 0.38 \mathrm{~mm})$ with a DC magnetron sputtering system (KENOSISTEC - KS40V). The working pressure was set at $0.09 \mathrm{~Pa} \pm 0.005$ to limit the scattering during gas transport. Indeed, in these conditions the mean free path is about $74 \mathrm{~mm}$ and with a target-to-substrate distance of $105 \mathrm{~mm}$, the average number of collisions is 1.4. Rectangular targets $(407 \mathrm{~mm} \times 127 \mathrm{~mm} \times 6.35 \mathrm{~mm}$ ) of the three metals are used: aluminum (purity of 99.99\%), chromium (purity of 99.95\%) and titanium (purity of 99.99\%). The negative discharge voltage of the aluminum, chromium and titanium targets was 464, 402 and $636 \mathrm{~V}$ 
respectively with a constant power of $1500 \mathrm{~W}$. The substrate-holder carries seven orientations $\alpha=0^{\circ}, 15^{\circ}, 30^{\circ}, 45^{\circ}, 60^{\circ}, 75^{\circ}$ and $85^{\circ}$ for each deposition with respect to the target normal (Fig. 1).

$\alpha$ is the angle between the substrate and target's normal. Positions of the substrate on the holder are chosen in order to minimize self-shadowing. Each holder has a width of $2 \mathrm{~cm}$ and the distance between two holders is $1 \mathrm{~cm}$. The deposition time was 16,19 and 35 min for aluminum, chromium and titanium coatings respectively. These durations were chosen in order to obtain $1 \mu \mathrm{m}$ thick layers for samples with an angle $\alpha=85^{\circ}$. This minimal value ensures that the stress measurements will be less influenced by the thickness variations [28].

The morphology of the cross section and the surface of the thin films were analyzed with a scanning electron microscope (SEM-Jeol JSM-5900 LV). From these observations, the thickness and the column angles $(\beta)$ with respect to the substrate normal in columnar microstructures of the thin films were determined. One should notice that increasing the substrate inclination leads to a gradient in the thickness over one direction, i. e over the direction targetsubstrate in the plane of both target and substrate normal (cut plane of Fig. 1). Indeed, smaller the target/substrate distance is, thicker the films are [16]. The film thickness mentioned in this study is an average value. The overall maximum variation of the thickness measurements is $\pm 0.1 \mu \mathrm{m}$.

The residual stresses of the thin films were evaluated using the wafer curvature technique and the modified Stoney's formula for a plate like substrate [29] was applied (Equation (1)):

$\sigma= \pm \frac{E}{6(1-v)} \times \frac{t_{s}^{2}}{t_{f}}\left(\frac{1}{R}\right)$

where $\mathrm{E}$ is the substrate's Young modulus, $v$ is the substrate's Poisson ratio, $t_{s}$ is the substrate's thickness and $t_{f}$ is the thickness of the thin films producing the stress, $\mathrm{R}$ the radius of curvature of the bended surface. The substrate curvatures, i.e. the topographic images of the whole substrate [30], before and after deposition were measured by optical profilometry (VEECO, Wyko NT-1100). The subtraction of the initial curvature image to the coated one allows obtaining the topographic image of the substrate deformation from where the radii are then extracted. This process and the extraction of the radii of the principal directions are performed by the Gwyddion software [31].

The incidence angle of the incoming particles was computed by

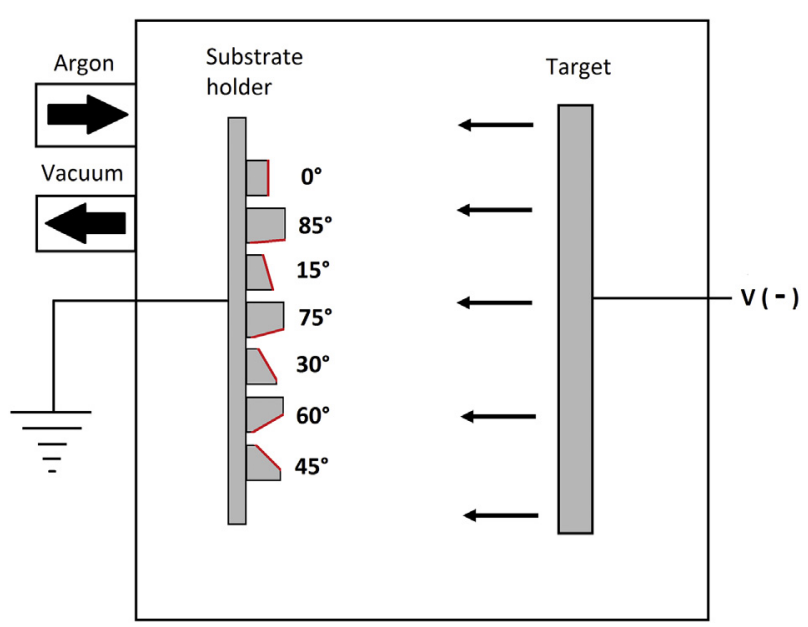

Fig. 1. Chamber description: On the left the substrate-holder is presented in the experimental configuration. The target and the substrate-holder are centered.
SIMTRA [32]. The calculations are based on the experimental settings (pressure, geometry and target erosion profiles) and TRIM calculations [33]. The angle used in this paper is calculated from the resultant vector of the particles impinging the substrate. Thus it is representative of the in-plane and the out of the plane distribution and also of the position and orientation of each substrate compared to the center of the target.

\section{Results and discussion}

\subsection{Thickness}

The normalized thickness of the $\mathrm{Al}, \mathrm{Cr}$ and Ti thin films and the normalized number of particles detected from SIMTRA calculations varying with the substrate inclination angle are illustrated in Fig. 2. When the substrate is facing the target, the thickness of the $\mathrm{Al}, \mathrm{Cr}$ and Ti coating is about $2.5,2.8$ and $2.35 \mu \mathrm{m}$ respectively.

The thickness of each coating depends on the number of atoms captured by the substrate surface. This amount is linked to the projected surface (parallel to the target plane), which evolution according to the orientation of the substrate is ruled by a cosine law, $\cos (\alpha)$, and will serve as a reference.

Two behaviors could be observed for the experimental data (Fig. 2-a): for $\alpha \leq 60^{\circ}$, the thickness of the $\mathrm{Al}, \mathrm{Cr}$ and Ti films decreases while the substrate inclination angle increases. The thickness evolution of the three materials follows globally the cosine law. Aluminum is the closest, where chromium is slightly higher. Titanium begins with a clear increase and then decreases with a higher slope than the cosine law. For these variations, a law, $\cos ^{\mathrm{s}}$ $(\alpha)$, proposed by Woo et al. [20] could fit the series. $s$ is a coefficient that takes into account the materials and the deposition conditions, without any direct physical signification. For $\alpha \geq 60^{\circ}$, the thickness of the films remains almost constant. The number of particles computed from SIMTRA calculations shows a similar trend with substrate inclination as the film thickness variation (Fig. 2-b). Below an angle of $60^{\circ}$, a cosine-like evolution is observed, although the values are higher than the cosine law. For $\alpha \geq 60^{\circ}$ computed values level off, and this effect is more pronounced for titanium than for chromium and aluminum. One can notice that the calculations predict more particles for $\alpha=15^{\circ}$ whatever the material. This is measured experimentally for chromium and titanium films. Especially for titanium, an increase of $10 \%$ compared to the normal deposition is reported.

Deviation from the cosine law has been also reported but mostly with a more continuous profile than the one reported here and often explained by a variation of the film mass density and a material effect $[23,24,34-36]$. In our case, the target could not be considered as a perfect punctual source as supposed in the cosine law. Consequently, the particular transport conditions, i.e. the scattering during transport, the shape of the racetracks, the size of the targets, the position of the samples relative to the center of the targets and a self-shadowing effect induced by the substrateholders, will moderate the simple cosine law that only depends on the substrate inclination angle. Fig. 3 present the calculated normalized number of particles versus the experimental normalized thickness.

A good linear correlation between the experimental and calculated results is found for all materials. Taking into account all the process parameters mentioned above and according to our particular system configuration, SIMTRA calculations confirm the influence of the particles transport on the thickness of the films. Some dispersion is observed between the thickness and the calculated number of particles and the particular behavior of each material. But, it is noteworthy that the thickness of a film is not only due to the number of impinging particles but also to the film morphology. 

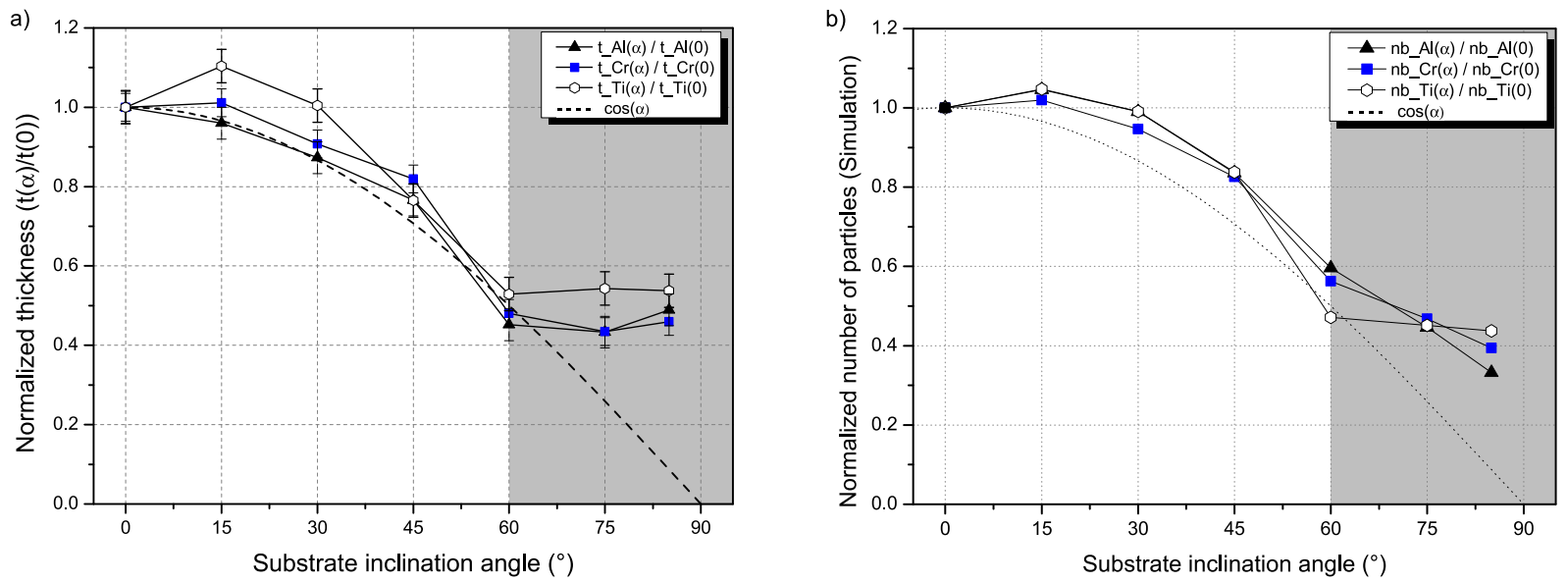

Fig. 2. a) Normalized thickness of the films versus the substrate inclination angle, b) normalized number of particles detected versus the substrate inclination angle.

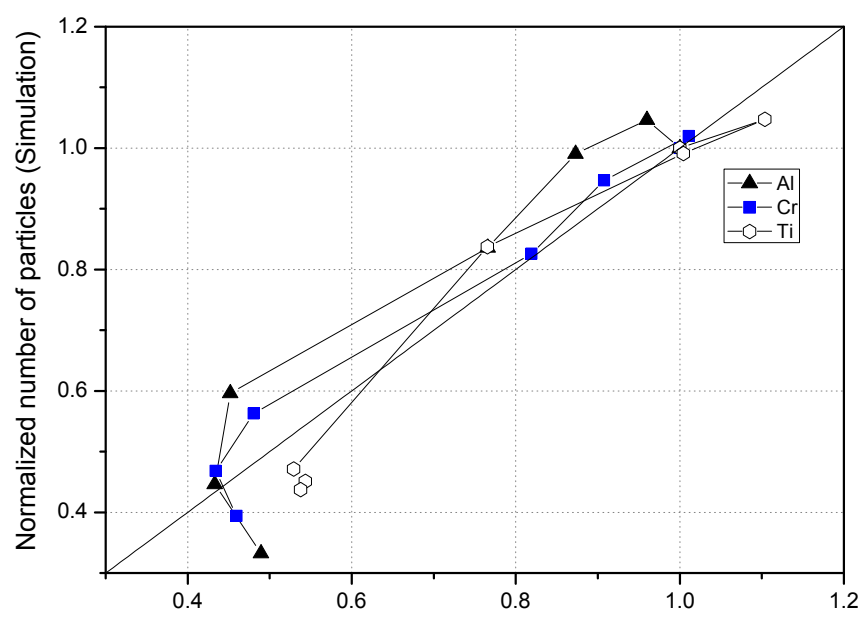

Normalized thicknesses (Experimental)

Fig. 3. Calculated normalized number of particles obtained from SIMTRA versus the experimental normalized thickness.

In particular, the column tilt angle, the mass density controlled by the incidence angle and the nature of the deposited material [37-39] will tuned the film thickness for a given number of particles.

Related to the thickness, an apparent critical angle could be fixed at $60^{\circ}$ for each material. For angles lower or equal to $60^{\circ}$ the thickness evolution follows approximately the cosine law or its variations. For higher angles, the evolution presents a strong and unusual deviation. These deviations are explained by simulation calculations. If the material seems to have a slight influence, the particles transport in the gas phase from the target to a substrate, linked to the particular configuration of the system, is predominant.

\subsection{Coatings morphology}

Fig. 4 presents the surface and the cross section morphologies of the films for $\alpha=0$ (upper panel) and $85^{\circ}$ (lower panel).

Surface morphology clearly depends on the angle of inclination of the substrate and the nature of the coating's material. At $\alpha=0^{\circ}$, the aluminum coating exhibits a relatively dense columnar structure with large crystallites (diameter around $300 \mathrm{~nm}$ ) randomly distributed on the surface. Chromium coatings present elongated columns perpendicular to the main direction of the incident flux, that could be the proof of the influence of the rectangular target shape linked to the substrate position. Titanium coatings are characterized by a dense nodular morphology. At $\alpha=85^{\circ}$, the structure of aluminum coatings presents a rough surface with crystallite columns randomly distributed, oriented towards the target. The diameter of the columns changes from 100 to $300 \mathrm{~nm}$. The high aluminum adatoms' mobility [40] explains the dense film at normal deposition and the formation of the large crystals with high porosity at oblique angle. The chromium films still present elongated columns perpendicular to the main direction of the incident flux. The void between the columns increased in comparison to the normal deposited film. For titanium, columns facing the flux with small hexagonal crystallites are observed. The same types of morphologies have previously been reported [41-44].

Fig. 5 presents the evolution of the column angles for the three materials versus the substrate inclination angle (Fig. 5-a) and versus the calculated incidence angle of the particles flux obtained from SIMTRA (Fig. 5-b).

The SEM cross section micrographs revealed the columnar microstructure of the deposited coatings and allowed to measure the column tilt angle. The evolution of this angle for each coating is compared with two theoretical models. The first one is a semiempiric law called the "tangent rule" $[45,46]$. However, this empirical formula is not really suitable for the substrates inclination angles $\alpha$ higher than $50^{\circ}$ [4]. The second model is a purely geometrical relation that derived from a ballistic model proposed by Tait et al. [37]. The column angles are normally smaller than the substrate inclination angles. Mostly, the experimental measurements present large deviations in comparison to the theoretical laws [41,42,47-51]. Following these works, the real relationship between $\alpha$ and $\beta$ is complex and seems to depend on the ballistic (i.e. the pressure, the geometry of the target, the target-to-substrate distance, etc.), on the composition of the films (i.e. number and nature of elements, crystalline structure, etc.), or on the temperature.

Indeed, in this study for the three metallic deposited materials, this deviation is also obvious for the column tilt angle versus the substrate inclination angle (Fig. 5-a). Two zones can be observed: below and above an angle around $50^{\circ}$. In the first zone, below $50^{\circ}$, the column angle increases with the orientation angle following the Tait's rule for aluminum layers and the tangent rule for chromium and titanium ones. Aluminum which is the lighter material $(A=27)$, presents more inclined columns than the heavy ones, chromium $(A=52)$ and titanium $(A=48)$. In the second zone, above $50^{\circ}$, stabilization, or level off, of the columns tilt occurs. If the 


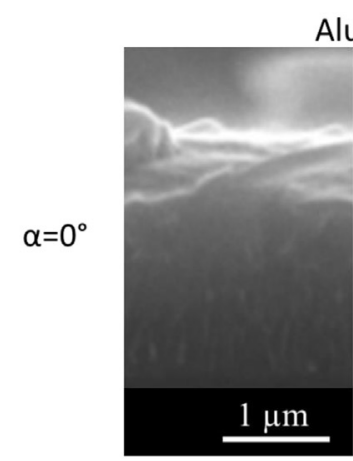

Aluminum
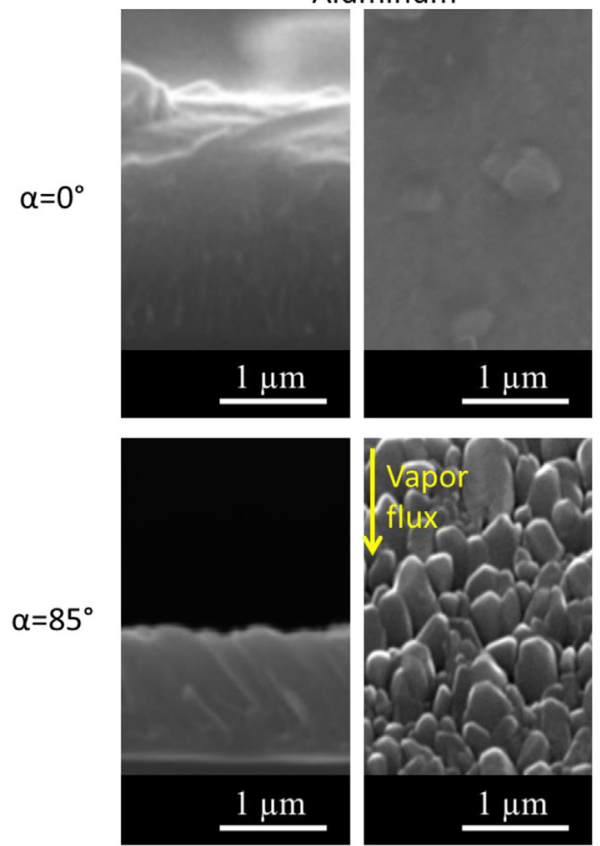
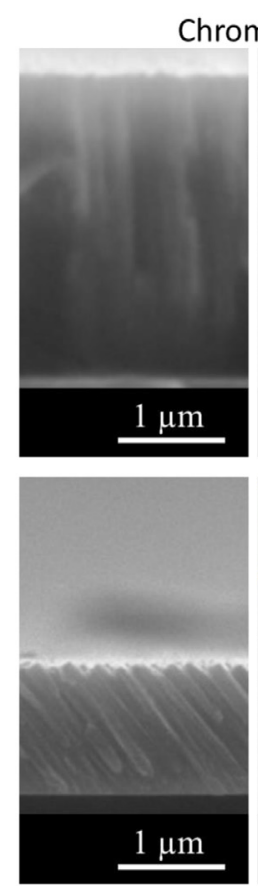

Chromium
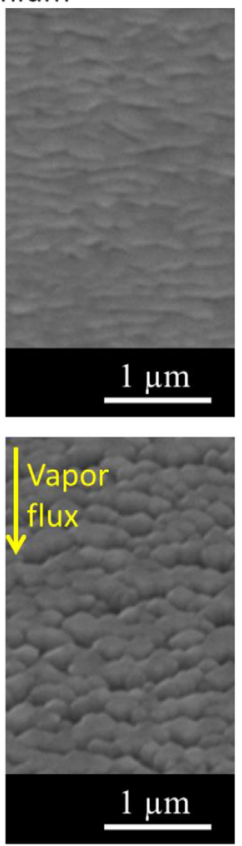

Titanium
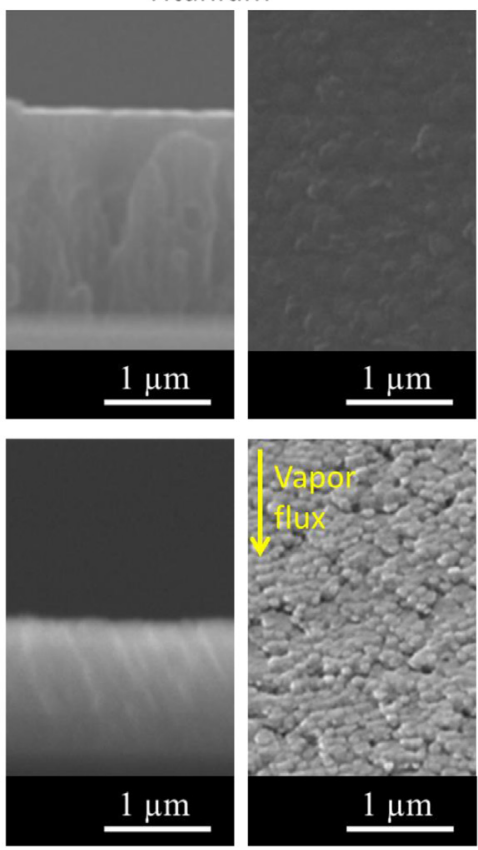

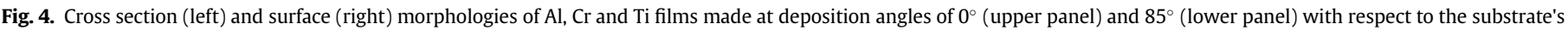
normal.

a)

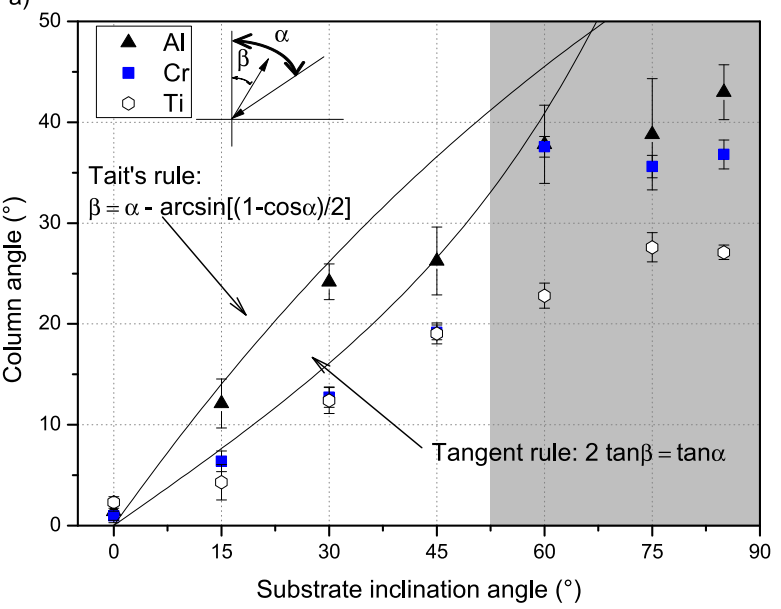

b)

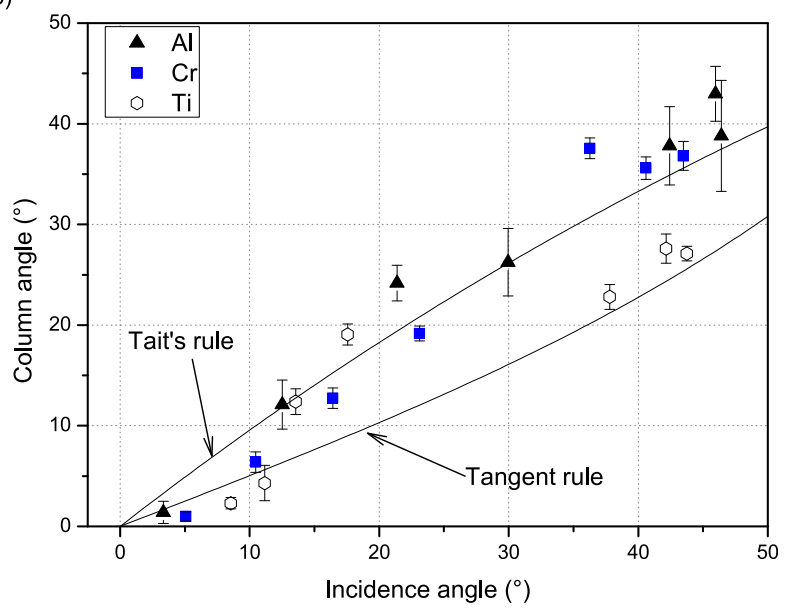

Fig. 5. $\mathrm{Al}, \mathrm{Cr}$ and $\mathrm{Ti}$ column tilt angle ( $\beta$ ) versus a) the substrate inclination angle and b) the calculated incidence angle of the particles flux obtained from SIMTRA.

evolution for aluminum and titanium is continuous, following a reduced Tait's law, the chromium columns angle presents a jump of $15^{\circ}$ for an inclination angle between 45 and $60^{\circ}$. This behavior, reproduced several times with different film thicknesses, is hardly understandable with the substrate inclination angle as reference and has never been reported previously.

Once again, at constant composition and temperature, the transport condition has a predominant influence. Indeed, the evolution of the column tilt angle versus the calculated incidence angle is in good agreement with the theoretical laws without any pronounced critical angle, nor strong deviation (Fig. 5-b). This means that the incidence angle and the substrate inclination angle are mostly different, especially in the case of sputtering. The incidence angle is a very local parameter that depends on several macroscopic parameters (see previous section) and the substrate inclination angle is just one of these macroscopic parameters. Only in some particular conditions, e.g. low pressure or small vapor sources, these angles could be merged. Because the substrate inclination angle is directly measured from the substrate-holder, its use is convenient as sample description, and should be carefully integrated for behaviors models elaboration.

Related to the columns tilt angle, an apparent critical substrate inclination angle could be fixed between 45 and $60^{\circ}$ especially for chromium. For aluminum and titanium, the evolution of the columns angle follows an attenuated Tait's rule without any specific critical angle. Nevertheless using the calculated incident angle, which is representative of the chamber configuration (target, substrate-holder, etc.) and the transport in the gas phase for each material, this evolution can be predicted with an acceptable accuracy by the theoretical laws. The residual variation should come from the other contribution to the columns growth: temperature and material properties. 
Hence, because the temperature is kept constant in this study, the following section investigates the intrinsic stresses of the layers.

\subsection{Residual stresses analyses}

In this last section the evolution of the stress states evaluated using the wafer curvature technique and the Stoney's formula is presented for the three materials versus the substrate inclination angle (Fig. 6-a). Indeed, one could have used the calculated incidence angle or the experimental column tilt angle, but it produces only a shift of the stress values without adding more information. So for convenience and because it describes well the different samples, the substrate inclination angle is still used, even if this parameter is not the only and dominant one to explain the film behavior (see previous section). As stress is induced partially by the flux energy [52,53], SIMTRA calculations are performed. The average energy of the impinging particles (metallic neutral) is obtained and the difference $\Delta \mathrm{E}_{\text {average }}$ in comparison to the result for a substrate at $\alpha=0^{\circ}(15.9,17.6$ and $23.8 \mathrm{eV}$ for $\mathrm{Al}, \mathrm{Cr}$ and Ti respectively) is presented versus the substrate inclination angle (Fig. 6-b).

The evolution of the stress state for the different samples is material dependent. The stress levels for sample under normal deposition conditions are consistent with some results found in the literature: Aluminum is compressive with a stress of $-150 \mathrm{MPa}$ ( -60 to $-80 \mathrm{MPa}$ [54]), Chromium is tensile at $350 \mathrm{MPa}$ (200-400 MPa [44]), Titanium is also tensile with values around $200 \mathrm{MPa}$ (50 MPa [54]).

With the change of substrate inclination a critical angle between 45 and $60^{\circ}$ is observed, especially for aluminum and titanium. Indeed, for $\alpha>60^{\circ}$, the absolute values of the stress suddenly drop to lower values. For aluminum, this corresponds to a transition from compressive to tensile stress. For chromium, this behavior is less obvious and another description could have been that stress is constant within the accuracy of measurements. But we assume that the previous decomposition in two zones is correct and justified by the observations made on aluminum and titanium.

The compressive/tensile change and the decrease of the absolute stress level in comparison to the substrate inclination angle have been previously reported $[29,55,56]$. The decrease of the stress level is explained by the increase of porosity, i.e. voids between the columns [29,57]. Indeed the density of GLAD films is known to decrease with the increase of the substrate inclination angle, especially for angle higher than $60^{\circ}[38,39,58,59]$.

a)

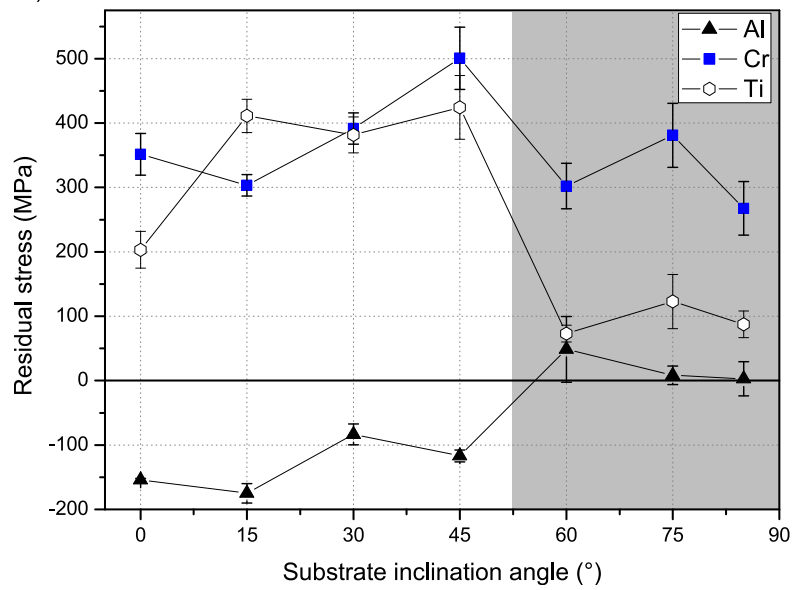

The stress state depends on adatoms' mobility and thus on the energy of the impinging particles. In this study, there is only one deposition for all substrate inclination. It means that the ejection energy distribution is the same for each sample and only the transport configuration with the parameters described in Section 3.1 will control the particles energy on the substrates. $\Delta \mathrm{E}_{\text {average, }}$ calculated from SIMTRA (Fig. 6-b) presents also two zones for $\alpha<60^{\circ}$ and for $\alpha>60^{\circ}$ with a remarkable correlation with the experimental stress measurements. In the first zone, i.e. for $\alpha<60^{\circ}$, the average particles energy increases with the substrate inclination angle. Experimentally, and relatively to each metal behavior, the stress follows the same trends. For chromium and titanium, the tensile stress increases to higher values, while for aluminum, the compressive stress decreases and tends to become tensile. This first increase of the particles energy leads to an increase of the tensile stress state. Between 45 and $60^{\circ}$ the particles energy decreases suddenly. Experimentally, it corresponds to a sudden decrease of the tensile stress (more marked for titanium) and a change from compressive to tensile stress for aluminum. For $\alpha>60^{\circ}$, the calculated energy increases, especially for aluminum and titanium, while the experimental stress remains almost constant. The drop at $\alpha=60^{\circ}$ could be explained by a filtering due to the position, orientation and inclination of the substrates. Indeed for this angle, the substrate is in the lower part of the substrate plate and oriented toward the bottom. Because $60^{\circ}$ remains a medium angle, low energetic particles due to high level of scattering still imping on the substrate. Consequently, the fraction of low energetic particles compared to high energetic particles increase. For higher angle, the target surface in view of the substrate increase (compared to $\alpha=60^{\circ}$ ), allowing an increase of the fraction of high energetic particles with low scattering. In the same time, the shadowing of the nearest holder and the high inclination angle tend to filter the low energetic particles with high scattering.

The stress state of a film depends on the material properties and the energy distribution of the sputtered or backscattered species [60]. In particular the density at grain boundary has a main role. In this study, the sputtering part is kept constant, and inclining the substrate has two effects: tuning the energy distribution on the substrate and increasing the intercolumnar voids due to selfshadowing during the growth. In the first zone where the density is still high, the main parameter influencing the stress is the energy increase, leading to higher tensile stress. The second zone is governed by a competition between both phenomena at two levels: (i) at grain level, the increase of the particles energy responsible for an b)

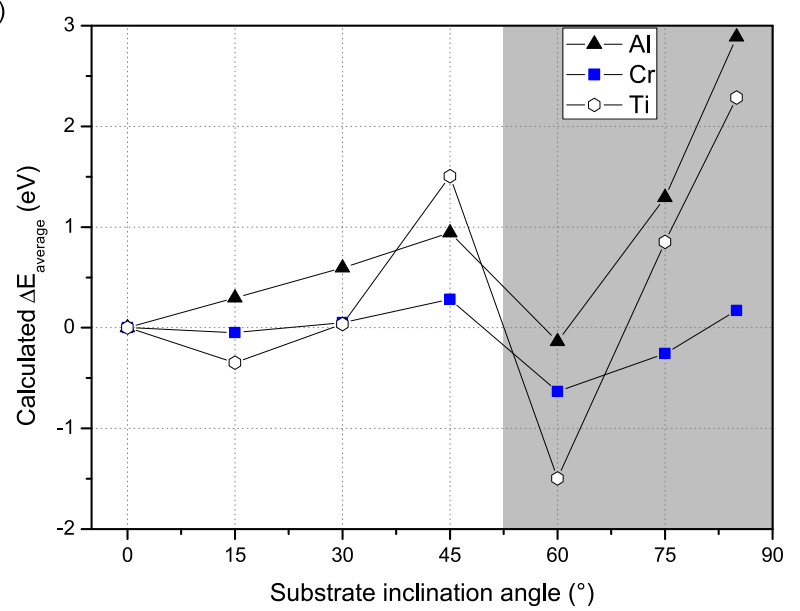

Fig. 6. a) Variation of the residual stresses of the $\mathrm{Al}, \mathrm{Cr}$ and Ti films versus the substrate inclination angles; b) $\Delta \mathrm{E}_{\text {average }}$ calculated by SIMTRA for the three materials. 
increase of the stress; (ii) at column level, the increase of the intercolumnar voids, which leads to the relaxation of the film stress. One can suggest that inside a polycrystalline column, the stress state remains almost constant.

Related to the stress analyses, an apparent critical angle could be defined around $60^{\circ}$. The stress level is not directly controlled by the incidence angle or the column tilt angle. Indeed, the transport condition in the gas phase, responsible of these angles, is also responsible for the particles energy and porosity evolution.

\section{Conclusion}

Three metallic materials were deposited on silicon substrates with the same deposition conditions (pressure, discharge power and target to substrate distance). A substrate-holder composed of seven different inclinations allowed to reduce the number of depositions (only one for each material). The properties of the obtained thin films revealed several points or critical zones in comparison to the substrate inclination angle:

- a critical angle $\alpha=60^{\circ}$ has been defined during the study of the layers thickness whatever the material,

- a critical angle between 45 and $60^{\circ}$, especially for chromium layers, has been determined during the columns tilt angles study,

- finally, a critical angle $\alpha=60^{\circ}$ was determined after studying the residual stresses.

It is noteworthy that the above mentioned critical angles are mostly apparent. Indeed, if the substrate inclination angle is a convenient macroscopic parameter to describe the different samples, it is also different from the real flux incident angle, especially in the case of magnetron sputtering. Then, it provides only a short and partial description of the flux that could influence the explanation of the measured properties evolution. Using SIMTRA calculations, the whole deposition conditions (racetrack profiles, targets dimension, position and orientation of the substrates relatively to the target, working pressure) can be taken into account. More relevant parameters are calculated to solve mainly the behavior of the following properties:

- the thicknesses are in good correlation with the calculated number of particles on each substrate,

- the column tilt angle evolution in comparison to the calculated incidence angle, is in good correlation with the theoretical laws,

- the stress variations are explained by the calculated energy of the particles and the film density.

Then, the remaining variations depend on the particular properties of the material deposited and of course of some approximation made by the simulation.

\section{Acknowledgements}

The authors wish to thank the French Government and especially the Ministry of Higher Education and Research for their financial support.

\section{References}

[1] K. Robbie, M.J. Brett, Sculptured thin films and glancing angle deposition: growth mechanics and applications, J. Vac. Sci. Technol. A 15 (1997) $1460-1465$.

[2] J.J. Steele, M.J. Brett, Nanostructure engineering in porous columnar thin films: recent advances, J. Mater. Sci. Mater. Electron 18 (2006) 367-379.

[3] Y.J. Jen, C.F. Lin, Anisotropic optical thin films finely sculptured by substrate sweep technology, Opt. Express 16 (2008) 5372.

[4] A. Besnard, N. Martin, C. Millot, J. Gavoille, R. Salut, Effect of sputtering pressure on some properties of chromium thin films obliquely deposited, IOP Conf. Ser. Mater. Sci. Eng. 12 (2010) 012015.

[5] R. Messier, V.C. Venugopal, P.D. Sunal, Origin and evolution of sculptured thin films, J. Vac. Sci. Technol. A 18 (2000) 1538-1545.

[6] M. Suzuki, Practical applications of thin films nanostructured by shadowing growth, J. Nanophot. 7 (2013) 073598, 1-10.

[7] Y.P. Zhao, D.X. Ye, P.I. Wang, G.C. Wang, T.M. Lu, Fabrication of Si nanocolumns and Si square spirals on self-assembled monolayer colloid substrates, Int. J. Nanosci. 01 (2002) 87-97.

[8] S.R. Kennedy, M.J. Brett, O. Toader, S. John, Fabrication of tetragonal square spiral photonic crystals, Nano Lett. 2 (2002) 59-62.

[9] D.X. Ye, T. Karabacak, R.C. Picu, G.C. Wang, T.M. Lu, Uniform Si nanostructures grown by oblique angle deposition with substrate swing rotation, Nanotechnology 16 (2005) 1717-1723.

[10] S.V. Kesapragada, P.R. Sotherland, D. Gall, Ta nanotubes grown by glancing angle deposition, J. Vac. Sci. Technol. B 26 (2008) 678-681.

[11] C.M. Zhou, D. Gall, The structure of Ta nanopillars grown by glancing angle deposition, Thin Solid Films 515 (2006) 1223-1227.

[12] A. Lakhtakia, Sculptured thin films: accomplishments and emerging uses, Mater. Sci. Eng. C 19 (2002) 427-434.

[13] J. Lintymer, N. Martin, J.M. Chappé, P. Delobelle, J. Takadoum, Nanoindentation of chromium zigzag thin films sputter deposited, Surf. Coat. Technol. 200 (2005) 269-272.

[14] S.V. Kesapragada, P. Victor, O. Nalamasu, D. Gall, Nanospring pressure sensors grown by glancing angle deposition, Nano Lett. 6 (2006) 854-857.

[15] J.P. Singh, F. Tang, T. Karabacak, T.M. Lu, G.C. Wang, Enhanced cold field emission from $\langle 100\rangle$ oriented $\beta-W$ nanoemitters, J. Vac. Sci. Technol. B 22 (2004) 1048-1051.

[16] J. Lintymer, J. Gavoille, N. Martin, J. Takadoum, Glancing angle deposition to modify microstructure and properties of sputter deposited chromium thin films, Surf. Coat. Technol. 174-175 (2003) 316-323.

[17] S.Y. Hsu, C.H. Tsai, C.Y. Lu, Y.T. Tsai, T.W. Huang, Y.H. Jhang, Y.F. Chen, C.C. Wu, Y.S. Chen, Nanoporous platinum counter electrodes by glancing angle deposition for dye-sensitized solar cells, Org. Electron 13 (2012) 856-863.

[18] R.D. McMichael, C.G. Lee, J.E. Bonevich, P.J. Chen, W. Miller, W.F. Egelhoff Jr., Strong anisotropy in thin magnetic films deposited on obliquely sputtered Ta underlayers, J. Appl. Phys. 88 (2000) 5296-5299.

[19] J.C. Sit, D. Vick, K. Robbie, M.J. Brett, Thin film microstructure control using glancing angle deposition by sputtering, J. Mater. Res. 14 (1999) 1197-1199.

[20] S.H. Woo, C.K. Hwangbo, Optical anisotropy of $\mathrm{TiO}_{2}$ and $\mathrm{MgF}_{2}$ thin films prepared by glancing angle deposition, J. Korean Phys. Soc. 49 (2006) 2136-2142.

[21] J.B. Sorge, M.J. Brett, Film morphology modification in ion-assisted glancing angle deposition, Thin Solid Films 519 (2010) 1356-1360.

[22] M. Levichkova, V. Mankov, N. Starbov, D. Karashanova, B. Mednikarov, K. Starbova, Structure and properties of nanosized electron beam deposited zirconia thin films, Surf. Coat. Technol. 141 (2001) 70-77.

[23] S. Wang, X. Fu, G. Xia, J. Wang, J. Shao, Z. Fan, Structure and optical properties of $\mathrm{ZnS}$ thin films grown by glancing angle deposition, Appl. Surf. Sci. 252 (2006) 8734-8737.

[24] A. Sinaoui, I. Trabelsi, F. Chaffar Akkar, F. Aousgi, M. Kanzari, Study of structural, morphological and optical properties of $\mathrm{Sb}_{2} \mathrm{~S}_{3}$ thin films deposited by oblique angle deposition, Int. J. Thin Films Sci. Technol. 3 (2014) 19-25.

[25] K.K. Kumar, P.M. Raole, P.A. Rayjada, N.L. Chauhan, S. Mukherjee, Study of structure development of Titanium Nitride on inclined substrates, Surf. Coat. Technol. 205 (2) (2011) S187-S191.

[26] H.Z. Yu, C.V. Thompson, Effects of oblique-angle deposition on intrinsic stress evolution during polycrystalline film growth, Acta Mater 77 (2014) 284-293.

[27] R. Alvarez, J.M. Garcia-Martin, A. Garcia-Valenzuela, M. Macias-Montero, F.J. Ferrer, J. Santiso, et al., Nanostructured Ti thin films by magnetron sputtering at oblique angles, J. Phys. Appl. Phys. 49 (2016) 045303.

[28] A.J. Detor, A.M. Hodge, E. Chason, Y. Wang, H. Xu, M. Conyers, et al., Stress and microstructure evolution in thick sputtered films, Acta Mater 57 (2009) 2055-2065.

[29] G.G. Stoney, The tension of metallic films deposited by electrolysis, Proc. R. Soc. Lond. Ser. Contain. Pap. Math. Phys. Character 82 (1909) 172-175.

[30] M.R. Ardigo, M. Ahmed, A. Besnard, Stoney formula: investigation of curvature measurements by optical profilometer, Adv. Mater. Res. 996 (2014) 361-366.

[31] D. Necas, P. Klapetek, Gwyddion: an open-source software for SPM data analysis, Cent. Eur. J. Phys. (2012) 181-188, 10(1), http://gwyddion.net/.

[32] K.V. Aeken, S. Mahieu, D. Depla, The metal flux from a rotating cylindrical magnetron: a Monte Carlo simulation, J. Phys. Appl. Phys. 41 (2008) 205307.

[33] J.F. Ziegler, M.D. Ziegler, J.P. Biersack, SRIM - the stopping and range of ions in matter, Phys. Res. B 268 (2010) 1818-1832.

[34] Y. Sato, K. Yanagisawa, N. Oka, S. Nakamura, Y. Shigesato, Sputter deposition of Al-doped ZnO films with various incident angles, J. Vac. Sci. Technol. A 27 (2009) 1166-1171.

[35] K. Wada, M. Yoshiya, N. Yamaguchi, H. Matsubara, Texture and microstructure of $\mathrm{ZrO}_{2}-4 \mathrm{~mol} \% \mathrm{Y}_{2} \mathrm{O}_{3}$ layers obliquely deposited by EB-PVD, Surf. Coat. Technol. 200 (2006) 2725-2730.

[36] G. Beydaghyan, K. Kaminska, T. Brown, K. Robbie, Enhanced birefringence in vacuum evaporated silicon thin films, Appl. Opt. 43 (2004) 5343.

[37] R.N. Tait, T. Smy, M.J. Brett, Modelling and characterization of columnar 
growth in evaporated films, Thin Solid Films 226 (1993) 196-201.

[38] S.M. Paik, S. Kim, I.K. Schuller, R. Ramirez, Surface kinetics and roughness on microstructure formation in thin films, Phys. Rev. B 43 (1991) 1843-1846.

[39] L. Wang, P. Clancy, Kinetic Monte Carlo simulation of the growth of polycrystalline Cu films, Surf. Sci. 473 (2001) 25-38.

[40] C.V. Thompson, Structure evolution during processing of polycrystalline films, Annu. Rev. Mater. Sci. 30 (2000) 159-190.

[41] A. Barranco, A. Borras, A.R. Gonzalez-Elipe, A. Palmero, Perspectives on oblique angle deposition of thin films: from fundamentals to devices, Prog. Mater. Sci. 76 (2016) 59-153.

[42] S. Mahieu, P. Ghekiere, D. Depla, R. De Gryse, Biaxial alignment in sputter deposited thin films, Thin Solid Films 515 (2006) 1229-1249.

[43] L. Chen, T.M. Lu, G.C. Wang, Incident flux angle induced crystal texture transformation in nanostructured molybdenum films, J. Appl. Phys. 112 (2012) 024303.

[44] Z.B. Zhao, S.M. Yalisove, Z.U. Rek, J.C. Bilello, Evolution of anisotropic microstructure and residual stress in sputtered Cr films, J. Appl. Phys. 92 (2002) $7183-7192$

[45] J.M. Nieuwenhizen, H.B. Haanstra, Microfractography of thin films, Philips Tech. Rev. 27 (1966) 87-90.

[46] M.M. Hawkeye, M.J. Brett, Glancing angle deposition: fabrication, properties, and applications of micro- and nanostructured thin films, J. Vac. Sci. Technol. A 25 (2007) 1317-1335.

[47] Y. Zhao, D. Ye, G.C. Wang, T.M. Lu, Designing nanostructures by glancing angle deposition, in: Proceedings of the SPIE, 2003, pp. 59-73.

[48] H. Zhu, W. Cao, G.K. Larsen, R. Toole, Y. Zhao, Tilting angle of nanocolumnar films fabricated by oblique angle deposition, J. Vac. Sci. Technol. B 30 (2012) 030606.
[49] B. Tanto, G.T. Eyck, T.M. Lu, A model for column angle evolution during oblique angle deposition, J. Appl. Phys. 108 (2010) 026107.

[50] H. Fujiwara, K. Hara, M. Kamiya, T. Hashimoto, K. Okamoto, Comment on the tangent rule, Thin Solid Films 163 (1988) 387-391.

[51] D. Depla, A. Besnard, J. Lamas, The influence of the pressure on the microstructure of yttria-stabilized zirconia thin films deposited by dual magnetron sputtering, Vacuum 125 (2016) 118-122.

[52] G. Abadias, W.P. Leroy, S. Mahieu, D. Depla, Influence of particle and energy flux on stress and texture development in magnetron sputtered TiN films, J. Phys. Appl. Phys. 46 (2013) 055301.

[53] D. Manova, J.W. Gerlach, S. Mändl, Thin film deposition using energetic ions, Materials 3 (2010) 4109-4141.

[54] W. Fang, C.Y. Lo, On the thermal expansion coefficients of thin films, Sens. Actuators Phys. 84 (2000) 310-314.

[55] C.C. Jaing, M.C. Liu, C.C. Lee, W.H. Cho, W.T. Shen, C.J. Tang, et al., Residual stress in obliquely deposited MgF2 thin films, Appl. Opt. 47 (2008). C266.

[56] J.A. Thornton, D.W. Hoffman, Stress-related effects in thin films, Thin Solid Films 171 (1989) 5-31.

[57] M.M. Hawkeye, M.T. Taschuk, M.J. Brett, Glancing Angle Deposition of Thin Films: Engineering the Nanoscale, John Wiley \& Sons, 2014.

[58] M.O. Jensen, M.J. Brett, Porosity engineering in glancing angle deposition thin films, Appl. Phys. A 80 (2004) 763-768.

[59] R.N. Tait, T. Smy, M.J. Brett, A ballistic deposition model for films evaporated over topography, Thin Solid Films 187 (1990) 375-384.

[60] D. Magnfält, G. Abadias, K. Sarakinos, Atom insertion into grain boundaries and stress generation in physically vapor deposited films, Appl. Phys. Lett. 103 (2013) 051910, 1-4. 